\title{
Optimal Sizing and Placement of Solar Cell Distributed Generator Suitable for Integrated Power System Environment
}

\author{
K. BANUMALAR, B. V. MANIKANDAN, K. CHANDRASEKARAN
}

\begin{abstract}
A novel fuzzified Clustered Gravitational Search Algorithm (CGSA) has been employed for solving multi-objective problem formulated for solar based distributed generation. Optimal sizing and placement of solar distributed generation is considered. High solar penetration can lead to high-risk level in power system reliability. In order to maintain the system reliability, solar power dispatch is usually restricted based on the reliability level of the system. Two conflicting objective functions such as power loss and reliability level of the system are also considered for solving optimal placement of solar distributed generation (SDG). Binary coded CGSA is employed for solving optimal placement of SDG and sizing is determined using real coded CGSA. The fuzzy membership function for each objective is designed and multi-objective optimal placement problem has been presented. The proposed method is validated on IEEE standard 69-bus radial distribution networks. The efficiency of the proposed optimization technique is validated by comparing the results with other results available in the existing articles.
\end{abstract}

Keywords: fuzzified gravitational search algorithm; multi objective optimal placement problem; reliability function; solar cell distributed generator

\section{INTRODUCTION}

Many power electric utilities around the world have been forced to change their way of operation from vertically integrated mechanism to open market system during the nineties, which is referred to as the "Deregulation of Power Industry". The deregulation of power industry is motivated by bringing competition among utility companies, new choices for customer, and economic benefits. Competition brings innovation, higher efficiency and lower costs, which is a win-win situation for both suppliers and consumers. Some other critical forces that drive power industry into deregulation are: the global economic crisis, more demanding environmental issues, and managerial inefficiency in regulated companies. The deregulation and environmental concerns bring interest in distributed generation (DG). DG refers to power generation at the point of consumption. Compared to the conventional centralised power plants, DG are sustainable, are smaller, and can be installed on or close to the customers to deliver power rather than the conventional way of transmitting power from centralized power plant over transmission. DG are expected to increase in the future.

Renewable generation technologies can make a significant contribution to the on-site power generation in developing countries. The use of solar energy sources is increasing throughout the world due to the concern regarding the benign nature to the environment. Solar based distributed generator (SDG) sources can reduce power loss and improve the quality of service with better voltage regulation. The recent growth of distribution technology provides an effective way for the use of renewable energy in the micro grid $[1,2]$. The distribution system defined by the Federal Energy Regulatory Commission is subject to reliability standards established through the North American Electric Reliability Corporation (NERC) as the Enforcement and Removal Operations (ERO) of United States of America (USA) [3]. The economic and technological growth of any nation depends on the reliable operation of electric power system. This forces the power utilities to consider reliability issues in the distribution system operation and control.
A literary review of DG placement problem models and the different solution techniques are given in $[4,5]$ with merits and demerits. A voltage stability index $[6,7]$ and power stability index [8] are developed for optimal placement of DG in distribution systems. A new analytical expression is proposed in [9] for finding optimal size of distributed generation and it is noticed that optimal power factor of DG for minimizing losses is in close agreement with load power factor and depends on location as well. In recent years, major focus of the system operators, decision makers and various stakeholders is to understand the current status, barriers and challenges for better planning and management in the field of solar based power generation [10].

Numerous techniques have been developed to incorporate reliability level as a constraint in the formulation of DG placement problem [11]. Maintaining the reliability level is an important task in the distribution system when considering a renewable distributed generator. The main idea of this article is maximizing the reliability level simultaneously handled in addition to the distribution system loss function and the proposed problem becomes multi objective optimization problem. Fuzzy based algorithms provide an efficient platform for solving the multi objective optimization problem. Hence, in this paper, fuzzified clustered gravitational search algorithm (CGSA) is also attempted to solve DG placement problem.

The aim of this paper is to implement reliability level of the distribution system as an objective function in a multi-objective optimal SDG placement problem. Fuzzy set theory affords an excellent platform for incorporating analytical and heuristic approaches in order to attain a more practical multi-objective problem formulation. The fuzzy membership function is designed and proposed for each objective function based on the nature of the objective. In this paper, a clustered GSA equipped with new workforce and integrated with fuzzy to solve multi-objective optimal SDG placement problem is proposed. The paper is organized as follows: Section 2 describes the problem formulation and Section 3 deals with review of clustered gravitational search algorithm. Results and Discussion are illustrated in Section 4 and Conclusion is outlined in Section 5 


\section{PROBLEM FORMULATION}

Modelling of power loss function and reliability of the distribution system for multi-objective SDG placement problem is presented below.

\subsection{Power Loss Index (PLI) Function}

Power Loss Index ( $P L I)$ is formulated by the Eq. (1) as (minimize):

$$
P L I=\frac{P_{L}}{P_{L}-P_{L-N O D G}}
$$

Where: $P_{L}$ and $P_{L-N O D G}$ are the total real power losses with and without DG units in the distribution system, respectively. The total real power loss $\left(P_{L}\right)$ is calculated using Eq. (2).

$$
\begin{aligned}
P_{L} & =\sum_{i=1}^{n} \sum_{j=1}^{n} A_{i j}\left(P_{i} P_{j}+Q_{i} Q_{j}\right)+B_{i j}\left(Q_{i} P_{j}-P_{i} Q_{j}\right) \\
A_{i j} & =\frac{R_{i j} \cos \left(\delta_{i}-\delta_{j}\right)}{V_{i} V_{j}} \\
B_{i j} & =\frac{R_{i j} \sin \left(\delta_{i}-\delta_{j}\right)}{V_{i} V_{j}}
\end{aligned}
$$

Where: $P_{i}, P_{j}, Q_{i}, Q_{j}$ and $R_{i j}$ are net real, reactive power and line resistance in bus $i$ and $j$ respectively; $V_{i}, V_{j}$ and $\delta_{i}$, $\delta_{j}$ are the voltage and angle at bus $i$ and $j$ respectively.

The above problem formulation is solved subject to the constraints listed below.

Voltage constraints: $\left|V_{i}\right|^{\min } \leq\left|V_{i}\right| \leq\left|V_{i}\right|^{\max }$

Current limits: $\left|I_{i j}\right| \leq\left|I_{i j}\right|^{\max }$

Where: $\left|V_{i}\right|^{\min }$ and $\left|V_{i}\right|^{\max }$ are the minimum and maximum limit of voltage in bus $i ;\left|I_{i j}\right|^{\max }$ is the maximum limit of current in bus $i$ and $j$.

\subsection{Distribution System Reliability Index Function}

Reliability model of solar generation, solar radiation model and solar based generation models are outlined in the proceeding section.

\subsubsection{Reliability Model of Solar Generation}

It is important to place SDG in areas of high mean annual solar radiation. The relation between the power output and solar radiation is shown in Fig. 1.

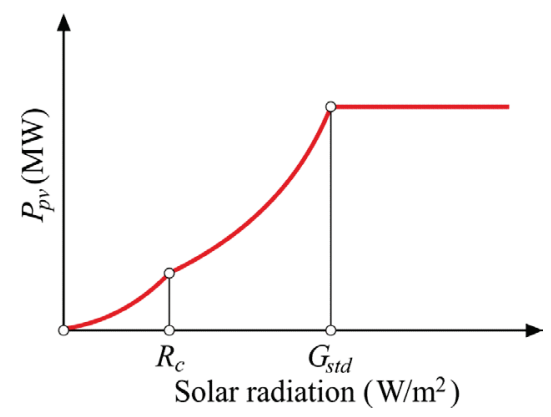

Figure 1 Power curve of Solar Distributed Generation

The power curve of SDG is mathematically $[12,13]$ expressed in Eq. (7). The SDG generated power $P_{b i}\left(G_{b i}\right)$ corresponding to a given solar radiation $G_{b i}$ for band $i$ ( $i=$ $1, \ldots, N_{b}$ ) can be obtained using Eq. (7) with $N_{b}$ being the total number of bands.

$$
\begin{aligned}
& P_{b i}\left(G_{b i}\right)=P_{s n} \frac{G_{b i}^{2}}{G_{s t d} \cdot R_{c}}, 0 \leq G_{b i} \leq R_{c} \\
& P_{b i}\left(G_{b i}\right)=P_{s n} \frac{G_{b i}}{G_{s t d}}, R_{c}<G_{b i}<G_{s t d} \\
& P_{b i}\left(G_{b i}\right)=P_{s n}, G_{b i}>G_{s t d}
\end{aligned}
$$

Where: $P_{b i}$ and $G_{b i}$ are the solar radiation-to-energy conversion and forecasted solar radiation at band $i ; G_{s t d}$ is the solar radiation in the standard environment set usually as $1,000 \mathrm{~W} / \mathrm{m}^{2} ; R_{c}$ is certain radiation point set usually as $150 \mathrm{~W} / \mathrm{m}^{2} ; P_{s n}$ is the equivalent rated capacity of the SDG (MW).

The solar energy conversion system contains one or more SDG. A SDG has two basic parts, namely solar resources and actual solar power generation system.

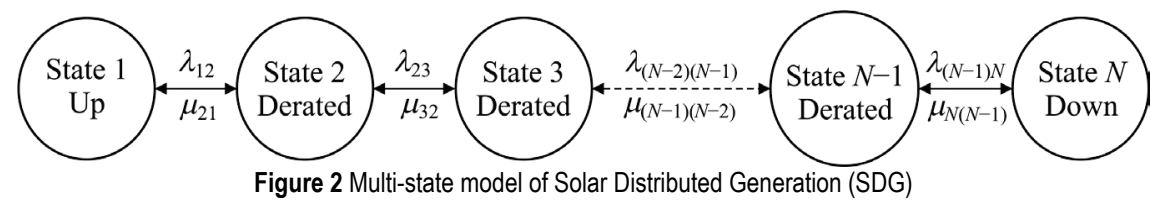

\subsubsection{Solar Radiation Model}

The conventional generating units can be modeled as a two state model for the reliability evaluation [14]. But, two state model is not suitable to reliability evaluation of solar cell generator (SDG) due to unstable solar radiation. Therefore, the multi-state model of operation of SDG forms a chain style as shown in Fig. 2. The multi state Solar radiation (SR) model of Jeju Island for the year 2007 is taken from [22]. The multi-state SR model, shown graphically in Fig. 3, based on the observed solar radiation can be reduced to different multistate Solar Radiation Capacity Outage Probability Table (SRCOPT) using rounding method [22].

In this paper, the five-state SRCOPT is formed, since it provides a reasonable reliability assessment in practical studies [15]. This five-state SRCOPT does not include SDG Forced Outage Rate (FOR). 


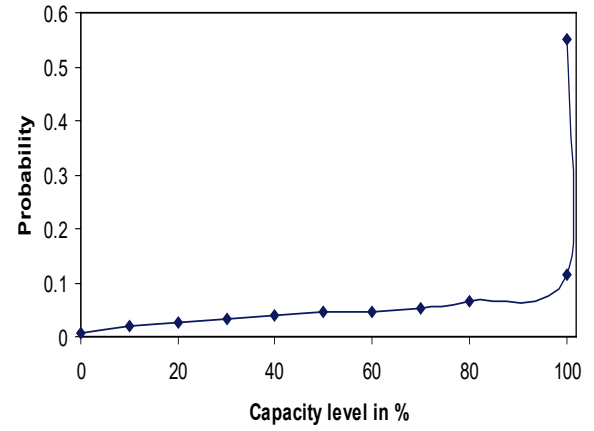

Figure 3 Capacity outage probability profile for SDG unit

\subsubsection{Solar Based Generation Model}

Steps to develop SDG COPT including FOR is shown in Fig. 4.

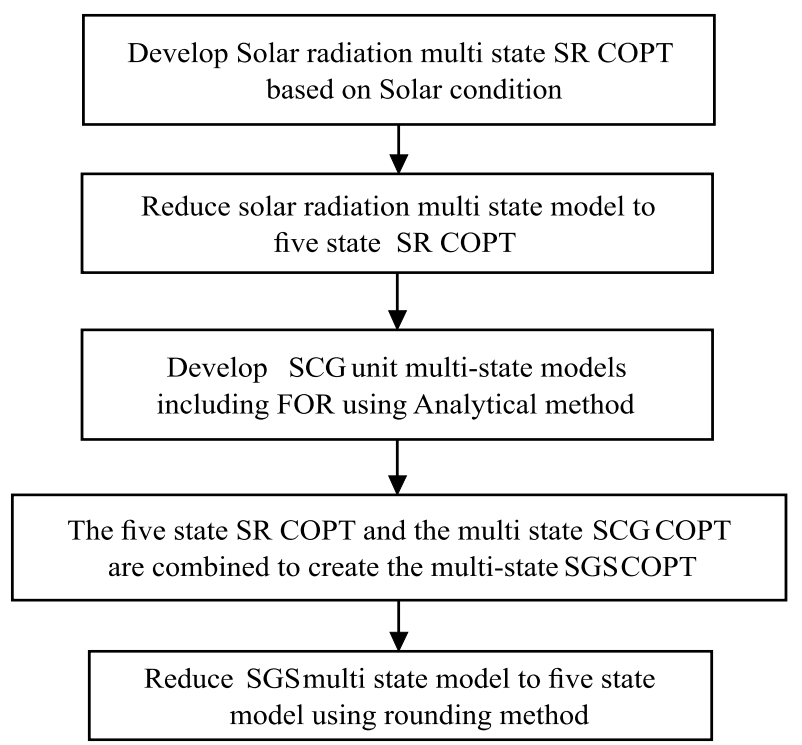

Figure 4 Proposed reliability model of SDG

The distribution system reliability index (DSRI) for each hour is calculated by Eq. (8).

$$
D S R I=\sum_{j=L C} p_{j}
$$

Where: $P_{j}$ is the probability of unavailability of state $j$ obtained from COPT subject to the constraints listed as Eqs. (5) - (6); $L C$ is the load curtailment.

\subsubsection{Multi Objective Problem Formulation}

The multi-objective optimal SDG placement problem is formulated as in Eq. (9) considering the power loss function and the reliability level of the distribution system simultaneously.

\section{Minimize (PLI, DSRI)}

The above equation is solved subject to the constraints listed in Eqs. (5) - (6). The membership function for best compromise solution based on maximum fitness $\left(F I T_{p}\right)$ is calculated by using Eq. (10).

$$
F I T_{p}=\frac{\left(\mu_{L}^{p}+\mu_{r}^{p}\right)}{\sum_{p=1 t o m}\left(\mu_{L}^{p}+\mu_{r}^{p}\right)}
$$

Where: $\mu_{L}^{p}$ and $\mu_{r}^{p}$ are the membership function values for the objective function PLI and DSRI; $m$ is the total number of non-dominated solutions.

\subsubsection{Fuzzy Membership Function Formulation}

The membership function for each objective function is designed based on the nature of the objective function, which indicates the level of satisfaction for getting the best compromise solution. The fuzzy membership function value for the objective function PLI and DSRI is calculated using the Eqs. (11) and (12) given below.

$$
\begin{aligned}
& \mu_{L}^{p}= \begin{cases}1, & \text { for } F_{L} \leq F_{L, \text { min }} \\
\frac{\left(F_{L, \max }-F_{L}\right)}{\left(F_{L, \text { max }}-F_{L, \text { min }}\right)}, & \text { for } F_{L, \text { min }}<F_{L}<F_{L, \text { max }} \\
0, & \text { for } F_{L} \geq F_{L, \text { max }}\end{cases} \\
& \mu_{r}^{p}= \begin{cases}0, & \text { for } F_{r} \leq F_{r, \text { min }} \\
\frac{\left(F_{r, \text { avg }}-F_{r}\right)}{\left(F_{r, \text { avg }}-F_{r, \min }\right)}, & \text { for } F_{r, \text { min }}<F_{r}<F_{r, \text { avg }} \\
\frac{\left(F_{r, \text { max }}-F_{r}\right)}{\left(F_{r, \text { max }}-F_{r, a v g}\right)}, & \text { for } F_{r, \text { avg }}<F_{r}<F_{r, \text { max }} \\
0, & \text { for } F_{r}>F_{r, \max }\end{cases}
\end{aligned}
$$

Where: $F_{L, \min }, F_{L, \max }$ are the minimum and maximum value of the objective function among all non dominated solutions respectively; $F_{r, \min }, F_{r \text {, avg }}, F_{r \text {, max }}$ are the minimum, average and maximum value of the DSRI function; $F_{L}, F_{r}$ are the degree of the PLI and DSRI in the fuzzy domain.

\section{GRAVITATIONAL SEARCH ALGORITHM}

In this algorithm, the coordinates or the agents in the search space are considered as masses. All these masses attract each other according to laws of Gravity and form a direct means of communication through it.The agents or particles in the algorithm follow the principles of Law of Gravity and Law of Motion [16, 17].

Consider a system with $N$ agents and the position of the $i^{\text {th }}$ agent being defined by the coordinates,

$$
X_{i}=\left(x_{i}^{1}, x_{i}^{2}, \ldots, x_{i}^{d}, \ldots, x_{i}^{n}\right) \text { for } i=1,2, \ldots, N
$$

where $x_{i}^{d}$ is the position of the $i^{\text {th }}$ agent in the $d^{\text {th }}$ dimension. At any time instant, the gravitational force acting on the $i^{\text {th }}$ particle due to the effect of the $j^{\text {th }}$ particle is given by,

$F_{i j}{ }^{d}(t)=G(t) \frac{M_{p i}(t) \times M_{a j}(t)}{R_{i j}(t)+\varepsilon}\left[x_{j}^{d}(t)-x_{i}^{d}(t)\right]$ 
Where: $G(t)$ is gravitational constant at time $t, \varepsilon$ is a small constant; $M_{a j}(t)$ and $M_{p i}(t)$ are the active and passive gravitational masses related to the particle $j$ and $i, R_{i j}(t)$ is the Euclidian distance between the particles (or agents) $i$ and $j$ which is given by,

$$
R_{i j}(t)=\left\|X_{i}(t), X_{j}(t)\right\|_{2}
$$

To give a random nature to the search, it is considered that the total force acting on the system $\left(F_{i}{ }^{d}(t)\right)$ is given by the weighted sum of the forces acting on the particle in the $d^{\text {th }}$ dimension due to all the other particles. It is given by the Eq. (15),

$$
F_{i}^{d}(t)=\sum_{j=1, j \# i}^{N} \operatorname{rand}_{j} F_{i j}^{d}(t)
$$

where rand $_{j}$ is a random number in the interval $[1,0]$. The acceleration of this agent in the $d^{\text {th }}$ dimension $\left(a_{i}{ }^{d}(t)\right)$ can be known by the Eq. (16),

$$
a_{i}^{d}(t)=\frac{F_{i}^{d}(t)}{M_{i i}(t)}
$$

where $M_{i i}$ is the inertial mass of the $i^{\text {th }}$ particle or agent.

Position and velocity of agent is calculated by the following Eqs. (17) - (18),

$$
\begin{aligned}
& v_{i}^{d}(t+1)=\operatorname{rand}_{i} \times v_{i}^{d}(t)+a_{i}^{d}(t) \\
& x_{i}^{d}(t+1)=x_{i}^{d}(t)+v_{i}^{d}(t+1)
\end{aligned}
$$

where $\operatorname{rand}_{i}$ is a random number in range $[0,1]$ to give a random characteristic to the search. Gravitational constant will reduce with time to control the speed and accuracy of the search, while its initial value shall be given earlier.

$$
G(t)=G\left(G_{0}, t\right)
$$

where, $G_{0}$ is the initial value of gravitational constant at the first cosmic time interval. Fitness evaluation gives the value to the gravitational and inertial masses, a higher fitness shows more efficient agent, resulting in more attraction and slow movement. The masses are calculated using the following Eqs. (20) - (22).

$$
\begin{aligned}
& M_{a i}=M_{p i}=M_{i i}=M_{i}, \quad i=1,2,3,4, \ldots \\
& m_{i}(t)=\frac{\operatorname{fit}_{i}(t)-\operatorname{worst}(t)}{\operatorname{best}(t)-\operatorname{worst}(t)} \\
& M_{i}(t)=\frac{m_{i}(t)}{\sum_{j=1}^{N} m_{j}(t)}
\end{aligned}
$$

where $f i t_{i}(t)$ is the fitness value which is determined by the function being optimized and worst $(t)$ and best $(t)$ are given by the following Eqs. (23) - (24).

$$
\begin{aligned}
& \operatorname{best}(t)=\left\{\begin{array}{l}
\min _{j \in\{1,2, \ldots N\}} f i t_{j}(t) \text { for minimization } \\
\max _{j \in\{1,2, \ldots N\}} f i t_{j}(t) \text { for maximization }
\end{array}\right. \\
& \operatorname{worst}(t)= \begin{cases}\max _{j \in\{1,2, \ldots N\}} f i t_{j}(t) & \text { for minimization } \\
\min _{j \in\{1,2, \ldots N\}} f i t_{j}(t) & \text { for maximization }\end{cases}
\end{aligned}
$$

Initially all the agents apply force at the time of exploration is going on. For better results in the final part of the search, the exploration fails and exploitation starts where only few more efficient agents continue to apply force. In order to avoid into local minima, exploration is allowed initially and gradually shifted to exploitation where only Kbest agents apply force. This Kbest set is decreased gradually to make the necessary change. The total force acting on the system incorporating Kbest set is given by Eq. (25) as,

$$
F_{j}^{d}(t)=\sum_{j \in K b e s t, j \# i} \text { rand }_{j} F_{i j}^{d}(t)
$$

where Kbest is the set of more efficient agents with more masses. This means that near the end of the iteration, nearly $2 \%$ of the initial particles shall only apply force. Many recent pieces of literature cited that GSA is successfully implemented for solving discrete and continuous optimization problem. In this paper, Clustered method is used to improve the performance of GSA which is discussed in the proceeding section.

\subsection{Clustered Gravitational Search Algorithm}

In this paper, a grouping method is proposed to balance the exploration and exploitation in GSA. Here the entire population is divided into three groups, namely the Leader, the follower and the freelancer. The best solution at the end of first iteration are Leaders particles. Each leader shall guide a group of optimizers and work together like a simple GSA population will search for optimum solution thereafter. The last group, the freelancers shall be randomly initiated for every iteration to keep the search active. Each group of those led by a leader and the freelancers shall have a best particle. The best out of these bests shall be the final best particle of the iteration. Based on the requirement of the function, the ratio of population of Leader, follower and the freelancer can be tuned.

Now there is no form of communication between the sub populations so they would always be searching independently (and exploring), rather than exploiting at the same place. The problem of exploitation is solved by the subgroups themselves. They exploit their local search spaces to get a minimum out of that region while since they do not communicate the exploration happens. The flowchart for the implementation of CGSA in the multi objective SDG placement problem is shown in Fig. 5.

\subsubsection{Implementation of CGSA for Solving DG Placement Problem}

In the optimal placement of SDG problem, binary numbers 1 and 0 are used to indicate the DG status (i.e., 1 indicates the DG is connected to the bus and 0 indicates 
DG is not connected to the bus). In GSA used in [16], the problem variables are real number, thus some modifications are required to deal with the binary variable optimization problem. As per the method given in [18], the real variable algorithm is converted into binary variable algorithm and implemented to solve optimal placement of SDG problem. The proposed binary coded CGSA finds the optimal location of SDG whereas the size of the SDG is determined by using real coded CGSA.

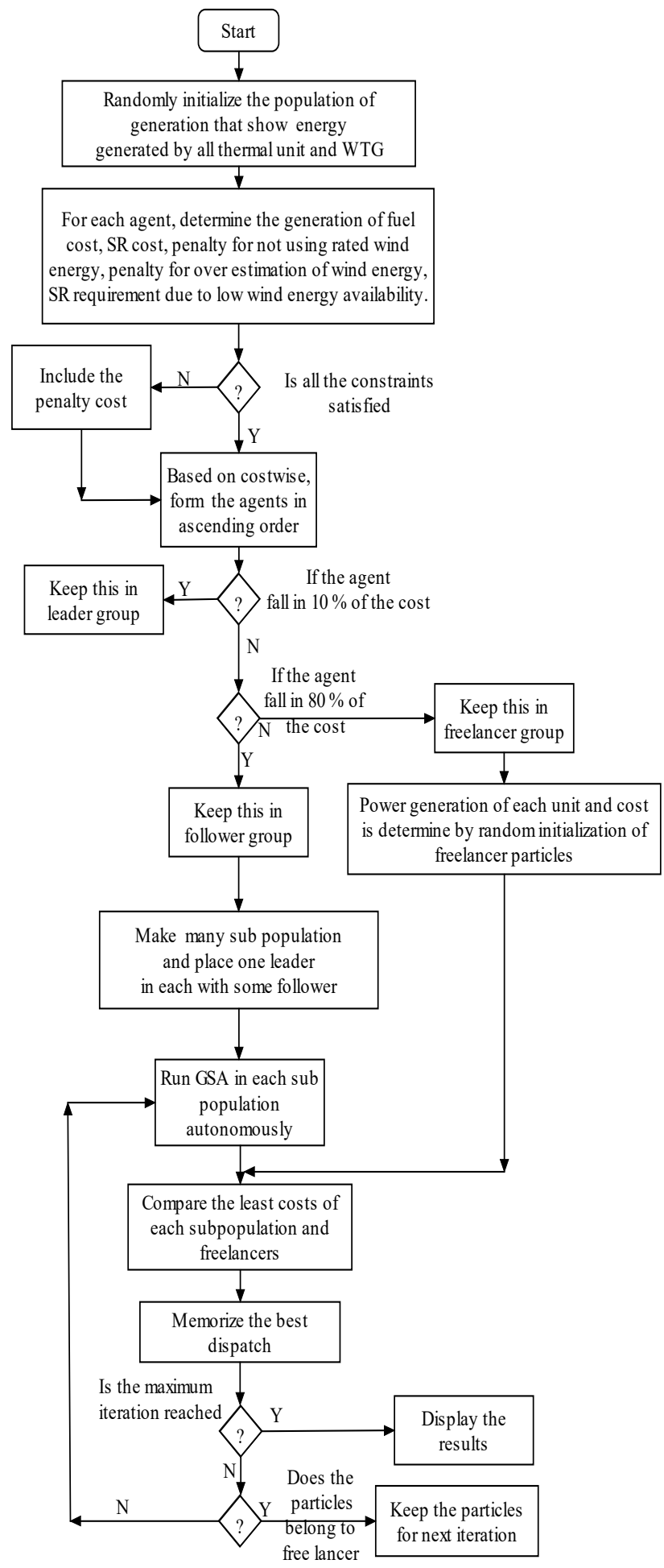

Figure 5 Flowchart for multi objective SDG placement problem using CGSA

\subsubsection{Implementation of CGSA for Solving Sizing Problem}

The grid integration points and sizes of DG units are determined by maximizing the FIT given in Eq. (10) using CGSA. The stepwise procedure for solving DG sizing is given below.

a) First Initialize the Number of DG unit is zero. Then determine the base case line flow, real and reactive power loss, and reliability index of the distribution system without any DG units.

b) Calculate the real power penetration at each bus to find the maximum limit of DG at particular bus.

c) Proper value of NDG is selected and then initialized the CGSA.

d) Make a random solution set of specified population size for NDG number of DG location-size pairs in the binary coded CGSA

e) For each population of binary CGSA, the real values are generated for the binary bit 1 based on the limit of the DG.

f) Compute the performance indices such as PLI and DSRI for each solution set.

g) FIT value is calculated for every solution set. From that, best solution is memorized with maximum fitness value.

h) For next iteration, the new position is obtained by implementing the CGSA algorithm.

i) The above steps $f$ to $h$ will be repeated until the iteration reaches maximum value.

j) Print the results; end.

\section{RESULTS AND DISCUSSION}

All programs are developed in MATLAB $10 \mathrm{~b}$ and run on system with Core 2 Duo $3.07 \mathrm{GHz}$ processor. Two case studies are discussed to validate the proposed methodology on IEEE standard 69-bus radial distribution networks. In case 1, the CGSA is used to solve optimal placement of SDG problem by considering the system loss as a single objective function and the results are compared with the results available in the published literature. In case 2 , multi objective optimal placement problem is solved using fuzzified CGSA. High solar power penetration in the distribution system can lead to high-risk level in distribution system reliability. In order to maintain the system reliability, in case 2 , optimal location and sizing of SDG is determined by considering two conflicting objective functions such as power loss and reliability level of the distributed system.

\subsection{Case 1}

The system data for 69 bus system is adopted from [19]. The system power loss is calculated as per the method suggested in [19]. The proper tuning of the CGSA parameters will result in better solution and good converge behaviour. Hence, the CGSA parameters are optimally tuned using trial and error method by conducting more than 15 simulations with each parameter settings.

The optimal tuned parameter to determine the optimal location and sizing of single and multiple SDG for 69 bus system is given in Tab. 1. Tab. 2 shows the best location and sizing of single DG for case 1 . It is noted that the 
objective function is significantly minimized in the proposed CGSA and it is able to provide better quality solution than other solution techniques available in the literatures. Also, the CGSA is tested to determine the optimal location of multi DG on 69 bus system.

Table 1 CGSA Parameters for 69 bus system

\begin{tabular}{|l|c|}
\hline \multicolumn{1}{|c|}{ CGSA Parameters } & Parameter value \\
\hline Population size & 100 \\
\hline No. of iterations & 300 \\
\hline G0 & 100 \\
\hline Alfa & 18 \\
\hline No. of clusters & 8 \\
\hline No. of leaders & 10 \\
\hline No. of followers & 80 \\
\hline No. of free lancers & 10 \\
\hline
\end{tabular}

Table 2 Solution for 69 bus system - Case 1 - Single SDG

\begin{tabular}{|l|c|c|c|}
\hline \multicolumn{1}{|c|}{ Techniques } & $\begin{array}{c}\text { Objective } \\
\text { function - } \\
\text { Power loss in } \\
\mathrm{kW}\end{array}$ & $\begin{array}{c}\text { DG } \\
\text { location }\end{array}$ & $\begin{array}{c}\text { Optimal sizing } \\
\text { in } \mathrm{kW}\end{array}$ \\
\hline PSI (19) & 83.142 & 61 & 1863.10 \\
\hline Novel power loss (19) & 83.195 & 61 & 1832.45 \\
\hline VSI search techniques (19) & 83.139 & 61 & 1870.00 \\
\hline CGSA (proposed) & $\mathbf{8 3 . 0 1 2}$ & $\mathbf{6 1}$ & $\mathbf{1 8 7 2 . 2 6}$ \\
\hline
\end{tabular}

Tab. 3 shows the best location and sizing of three DG for case 1 and it is observed that the total system losses are significantly reduced compared with GA [20], PSO [20] and GA-PSO [20]. Also, the sizing of SDG has greatly optimized with the proposed CGSA method.

Table 3 Solution for 69 bus system - Case 1 - Multi SDG

\begin{tabular}{|l|c|c|c|}
\hline \multicolumn{1}{|c|}{ Techniques } & $\begin{array}{c}\text { Objective } \\
\text { function - Power } \\
\text { loss in } \mathrm{kW}\end{array}$ & $\begin{array}{c}\text { Multi DG } \\
\text { location }\end{array}$ & $\begin{array}{c}\text { Optimal sizing } \\
\text { in } \mathrm{kW}\end{array}$ \\
\hline GA (20) & 89.0 & $21,62,64$ & $\begin{array}{c}929.7,1075.2, \\
984.8\end{array}$ \\
\hline PSO (20) & 83.2 & $61,63,17$ & $\begin{array}{c}1199.8,795.6, \\
992.5\end{array}$ \\
\hline GA-PSO(20) & 81.1 & $63,61,21$ & $\begin{array}{c}884.9,1192.6, \\
910.5\end{array}$ \\
\hline CGSA (proposed) & $\mathbf{6 9 . 4 3}$ & $\mathbf{1 1 , 1 8 , 6 1}$ & $\begin{array}{c}\mathbf{5 2 7 . 1 , 3 8 0 . 4} \\
\mathbf{1 7 1 9 . 2}\end{array}$ \\
\hline
\end{tabular}

Table 4 Comparison of results

\begin{tabular}{|l|c|c|c|}
\hline \multicolumn{1}{|c|}{ Table 4 Comparison of results } \\
\hline Techniques & $\begin{array}{c}\text { Objective function - } \\
\text { Power loss in kW }\end{array}$ & $\begin{array}{c}\text { Multi DG } \\
\text { location }\end{array}$ & $\begin{array}{c}\text { Frequency of } \\
\text { achieving } \\
\text { best result }\end{array}$ \\
\hline GA & 88.533 & $21,63,64$ & 7 \\
\hline PSO & 76.325 & $61,63,22$ & 11 \\
\hline CGSA & 73.131 & $20,21,61$ & 10 \\
\hline
\end{tabular}

\subsubsection{Performance Analysis}

The algorithm efficiency and the performance of the proposed algorithm is validated by solving the optimal location and sizing of DG problem using standard GA, PSO and GSA and the results are discussed. In all the four solution techniques (GA, PSO, GSA and CGSA), the population size and the maximum number of iterations are fixed as the same. Also the random generated initial population is considered as same for all four algorithms. Tab. 4 shows the comparison of result CGSA with GA, PSO and GSA. Convergence behaviour of GA, PSO, GSA and CGSA is shown in Fig. 6. From Tab. 4 and Fig. 6, it can be concluded that the CGSA is computationally efficient and has high frequency of achieving best result than other considered algorithms like GA, PSO and GSA.

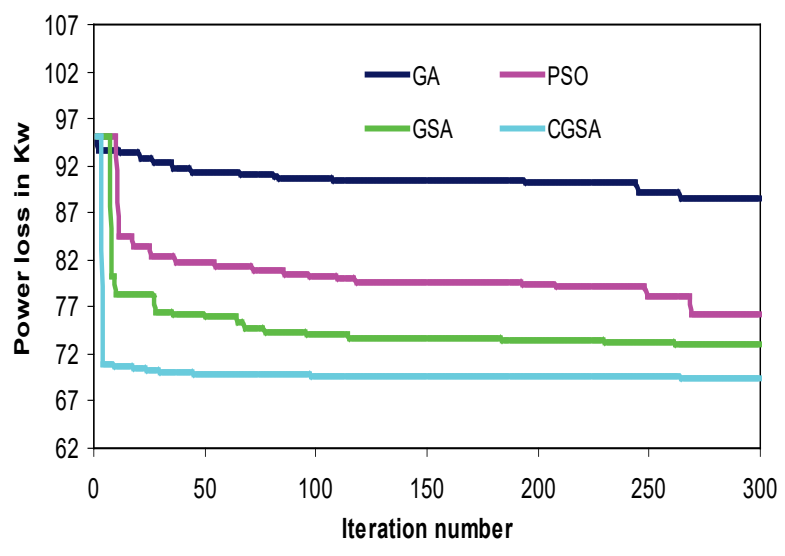

Figure 6 Convergence graph for IEEE 69 bus system

\subsection{Case 2}

Power system reliability can be affected by high solar diffusion. Therefore, to maintain the system reliability, solar power dispatch is restricted based on reliability level of the system. Therefore, the SDG location and sizing method discussed under section 4.1 does not provide a satisfactory solution.

Hence, it stresses the need for the formulation of multi objective optimal placement and sizing problem to obtain a best compromise solution between the Power loss and Reliability level. In the proposed methodology, the two contradictory objective functions such as power loss and reliability level of the system are considered to solve optimal placement of SDG problem.

In this section, the location and sizing of SDG is determined by considering the objective function power loss and reliability level simultaneously using Fuzzified CGSA. The fuzzy membership function is used to determine the best compromise solution. Typical available minimum and maximum rating of SDG in the market is from $1 \mathrm{MW}$ to $10 \mathrm{MW}$ [21].

\subsubsection{Modelling and Simulation of Solar Irradiation Data}

The determination of a proper solar radiation for a solar panel location is a complicated process. It is required to collect solar irradiation historical data over a significant period of time.

In [22], the common solar irradiation model is developed to obtain the solar irradiation probability distribution for any geographical location. The only data that are required are the annual mean $(\omega)$ of the solar irradiation for that site. In this section, the rated capacity of the SDG is considered as $4 \mathrm{MW}$. As per the steps given in section 2.2.3, the outage capacity for SDG is calculated for the above specification and given in Tab. 5 .

Table 5 The five state model of Single SDG

\begin{tabular}{|c|c|c|c|c|c|}
\hline FOR (MW) & 4 & 3 & 2 & 1 & 0 \\
\hline FOR & 0.6615 & 0.087627 & 0.14529 & 0.078012 & 0.2753 \\
\hline
\end{tabular}

Similarly, three SDG are considered in the 69 bus system. The distribution system reliability index is 
calculated using Eq. (8) and the fuzzy fitness is calculated using Eq. (10).

Table 6 Fuzzified CGSA solution for various Irradiation - Case 2- Multi SDG problem

\begin{tabular}{|c|c|c|c|c|}
\hline $\begin{array}{c}\text { Solar } \\
\text { irradiation } \\
/ \mathrm{W} / \mathrm{m}^{2}\end{array}$ & $\begin{array}{c}\text { Objective } \\
\text { function } \\
\text { power loss } \\
/ \mathrm{kW}\end{array}$ & $\begin{array}{c}\text { Objective } \\
\text { function } \\
\text { DSRI }\end{array}$ & $\begin{array}{c}\text { Multi } \\
\mathrm{DG} \\
\text { location }\end{array}$ & $\begin{array}{c}\text { Optimal } \\
\text { sizing } / \mathrm{kW}\end{array}$ \\
\hline 700 & 112.97 & 0.6577 & $21,62,64$ & $\begin{array}{c}492.33,412.25, \\
1098.00\end{array}$ \\
\hline 800 & 98.42 & 0.4611 & $11,18,61$ & $\begin{array}{c}412.77,56.33, \\
1125.97\end{array}$ \\
\hline 900 & 83.15 & 0.3856 & $11,17,64$ & $\begin{array}{c}318.25,387.12, \\
1358.12\end{array}$ \\
\hline 1000 & 81.23 & 0.3215 & $11,21,61$ & $\begin{array}{c}429.71,314.34, \\
1421.97\end{array}$ \\
\hline
\end{tabular}

The best compromise solution for optimal location and sizing of multi SDG at different solar irradiation is given in Tab. 6. From Tab. 6, it has been proved that, if the solar irradiation decreases, then the reliability level of the distribution system also decreases and power loss gets increased. It is evident that, if the solar irradiation is known for any particular site, then the corresponding output of SDG can be calculated using the proposed methodology.

\section{CONCLUSION}

In this paper, the Gravitational Principle has been used to search the optimum solution. The proposed fuzzy based CGSA has been presented for solving multi objective optimal placement and sizing of SDG problem. The problem has been formulated as a multi objective problem with distribution system losses and reliability level of the distribution function. The fuzzy set theory is implemented to eliminate the dependence of entire global preference information of decision maker in a multi objective problem and give a single compromise solution. Thereby, the limitation such as the trade-off between the system losses and reliability level of the distribution system in selecting a feasible solution from a set of population solutions is circumvented. The results presented for the selected test system established the fact that the proposed CGSA approach is superior to the other considered algorithms. The proposed methodology can be very well extended to the smart grid environment with demand side management, which is deemed to be fit for future scope of research.

\section{REFERENCES}

[1] Nikmehr, N. \& Najafi-Ravadanegh, S. (2015). Optimal operation of distributed generations in micro-grids under uncertainties in load and renewable power generation using heuristic algorithm. IET Renewable Power Generation, 9(8), 982-990. https://doi.org/10.1049/iet-rpg.2014.0357.

[2] Karakosea, M., Baygina, M., Murata, K., Bayginb, N., \& Akina, E. (2016). Fuzzy Based Reconfiguration Method Using Intelligent Partial Shadow Detection in PV Arrays. International Journal of Computational Intelligence Systems, 9(2), 202-212. https://doi.org/10.1080/18756891.2016.1150004

[3] NERC, Becoming the New NERC 2007, cited Apr. 14, 2007.

[4] Georgilakis, P. S. \& Hatziargyriou, N. D. (2013). Optimal Distributed Generation Placement in Power Distribution Networks: Models, Methods, and Future Research. IEEE Transactions on Power System, 28(3), 3420-3428.
https://doi.org/10.1109/TPWRS.2012.2237043

[5] Abbasi, F. \& Hosseini, S. M. (2015). Optimal DG allocation and sizing in presence of storage systems considering network configuration effects in distribution systems. IET Generation, Transmission \& Distribution, 10(3), 617- 624. https://doi.org/10.1049/iet-gtd.2015.0367

[6] Naik, S. N. G., Khatod, D. K., \& Sharma, M. P. (2015). Analytical approach for optimal siting and sizing of distributed generation in radial distribution networks. IET Generation, Transmission \& Distribution, 9(3), 209-220. https://doi.org/10.1049/iet-gtd.2014.0603

[7] Jamshidi, B., Saghaei, A., Zare, A., Safari, M., \& Golmohamadi, A. (2012). Voltage profile quality of conformance evaluation with process capability analysis in the presence of distributed generation. Proc. of the IEEE, 14. https://doi.org/10.1049/cp.2012.0827

[8] Aman, M., Jasmon, G. B., Mokhlis, H., \& Bakar, A. H. A. (2012). Optimal placement and sizing of a DG based on a new power stability index and line losses. Electrical Power and Energy Systems, 43, 1296-1304. https://doi.org/10.1016/j.jiepes.2012.05.053

[9] Viral, R. \& Khato, D. K. (2015). An analytical approach for sizing and siting of DGs in balanced radial distribution networks for loss minimization. International Journal of Electrical Power \& Energy Systems, 67, 191-201. https://doi.org/10.1016/j.ijepes.2014.11.017

[10] Karan Kapoora, Krishan Pandeya, K., Jaina, A. K., \& Ashish Nandan. (2014). Evolution of solar energy in India: A review. Renewable Energy and Sustainable Reviews, 40, 475-487. https://doi.org/10.1016/j.rser.2014.07.118

[11] Rasdi, M. R. H. M., Musirin, I., Hamid, Z. A., \& Haris, H. C. M. (2014). Gravitational search algorithm application in optimal allocation and sizing of multi distributed generation. Power Engineering and Optimization Conference (PEOCO), IEEE, 364-368. https://doi.org/10.1109/PEOCO.2014.6814455

[12] Nikmehr, N. \& Najafi-Ravadanegh, S. (2015). Optimal power dispatch of multi-microgrids at future smart distribution grids. IEEE Transaction on Smart Grid, 6(4), 1648-1657. https://doi.org/10.1109/TSG.2015.2396992

[13] Aien, M., Fotuhi-Firuzabad, M., \& Aminifar, F. (2014). Probabilistic optimal power flow in correlated hybrid windphotovoltaic power systems. IEEE Transaction on Smart Grid, 5(1), 130-138. https://doi.org/10.1109/TSG.2013.2293352

[14] Simopoulos, D. N., Kavatza, S. D., \& Vournas, C. D. (2006). Reliability constrained unit commitment using simulated annealing. IEEE Transaction on Power Systems, 21(4), 1699-1706. https://doi.org/10.1109/TPWRS.2006.881128

[15] Gao, Y., Billinton, R., \& Karki, R. (2008). Composite generation and transmission system reliability evaluation incorporating two wind energy facilities considering wind speed correlation. $40^{\text {th }}$ North American Power Symposium NAPS '08, 1-7. https://doi.org/10.1109/NAPS.2008.5307377

[16] Rashedi, E., Nezamabadi, H., \& Saryazdi, S. (2009). GSA: A gravitational search algorithm. Information Sciences, 178, 2232-2248. https://doi.org/10.1016/j.ins.2009.03.004

[17] Halliday, D., Resnick, R., \& Walker, J. (1993). Fundamentals of physics, John Wiley and Sons.

[18] Chandrasekaran, K. \& Sishaj, P. S. (2013). Optimal Deviation based Firefly Algorithm Tuned Fuzzy Design for Multi-Objective UCP. IEEE Transaction on power systems $U C P, 28(1), 460-471$. https://doi.org/10.1109/TPWRS.2012.2201963

[19] Murty, V. V. S. N., \& Kumar, A. (2015). Optimal placement of DG in radial distribution systems based on new voltage stability index under load growth. Electrical Power and Energy Systems, 69, 246-256. https://doi.org/10.1016/j.jiepes.2014.12.080

[20] Moradi, M. H. \& Abedini, M. A. (2012). Combination of genetic algorithm and particle swarm optimization for 
optimal DG location and sizing in distribution systems. Electrical Power and Energy Systems, 34, 66-74. https://doi.org/10.1109/IPECON.2010.5697086

[21] Dulau, L. I., Abrude, M., \& Bica, D. (2014). Distributed generation technologies and optimization. Procedia Technology, 12, 687-692. https://doi.org/10.1016/j.protcy.2013.12.550

[22] Park, J., Liang, W., Choi, J., El-Keib, A. A., Shahidehpour, M., \& Billinton, R. (2009). A Probabilistic Reliability Evaluation of a Power System Including Solar/Photovoltaic Cell Generator. 2009 IEEE Power \& Energy Society General Meeting, Calgary, AB, 1-6.

https://doi.org/10.1109/PES.2009.5275722

\section{Contact information:}

\section{K. BANUMALAR, Research Scholar}

Corresponding author

Faculty of Electrical and Electronics Engineering,

Mepco Schlenk Engineering College,

Mepco Nagar, Virudhunagar, Sivakasi, Tamil Nadu 626005, India

banumalar.234@gmail.com

\section{B. V. MANIKANDAN, Professor, Dr.}

Faculty of Electrical and Electronics Engineering

Mepco Schlenk Engineering College,

Mepco Nagar, Virudhunagar, Sivakasi, Tamil Nadu 626005, India

bvmani73@yahoo.com

\section{K. CHANDRASEKARAN, Professor, Dr.}

Faculty of Electrical and Electronics Engineering,

National Institute of Technology Puducherry,

Thiruvettakudy, Karaikal, Puducherry 609609, India

chansekaran23@gmail.com 